\title{
One Stop Neck Lump Clinic- A boon for quick diagnosis and early management
}

\author{
Tarun Sood $^{1}$, Mrinal Supriya ${ }^{1}$, Jacob Thopil ${ }^{1}$, Vishak Surendra ${ }^{1}$, and Barun Patel $^{2}$ \\ ${ }^{1}$ Northampton General Hospital \\ ${ }^{2}$ Armed Forces Medical Services
}

November 16, 2020

\begin{abstract}
Abstract Introduction: One stop neck lump clinics (OSNLC) are gaining popularity worldwide especially in the UK hospitals following NICE recommendation. The main aim of this speciality clinic is quick diagnosis and early management while simultaneously improving patient experience. Objectives: To analyse and compare the efficacy of OSNLC and general ENT/Head and neck clinic with specifics to number of appointments required for formulating management plan and number of 'one stop' visits. Design: Retrospective observational study Setting: Regional Head and Neck Cancer Center (Secondary care hospital) Participants: Patients referred by General practitioner with symptoms of neck lump Main outcome measures: Patients seen in general ENT/Head and neck and OSNLC in 2 phases to understand the difference in number of appointments, one stop visits, requirement of Ultrasound and efficiency of Fine needle aspiration. Results and Conclusions: Improved efficacy of OSNLC was noted as patients seen in clinic required lesser number of appointments, reached a faster diagnosis and management plan when compared to patients seen in general ENT clinic.
\end{abstract}

\section{Hosted file}

Article One stop Neck lump.pdf available at https://authorea.com/users/376344/articles/ 493319-one-stop-neck-lump-clinic-a-boon-for-quick-diagnosis-and-early-management 